Historic, Archive Document

Do not assume content reflects current scientific knowledge, policies, or practices. 

$62,9,1$

1

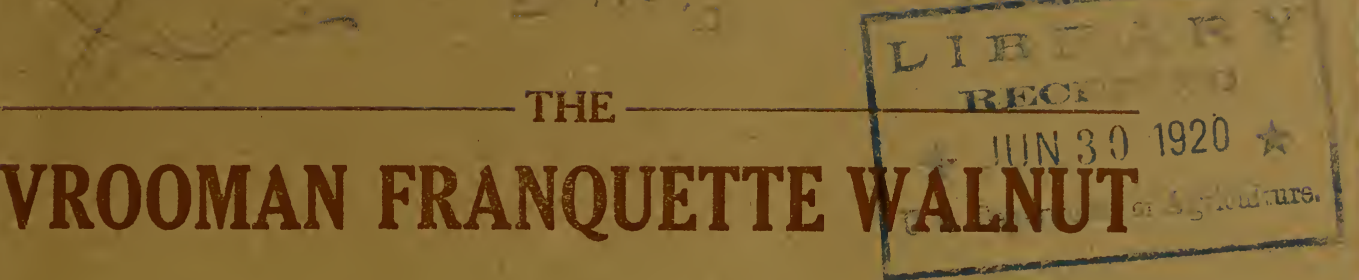

A HARDY, PRODUCTIVE TREE

PRODUCING A

LARGE, DELICIOUS, NUTRITIOUS NUT

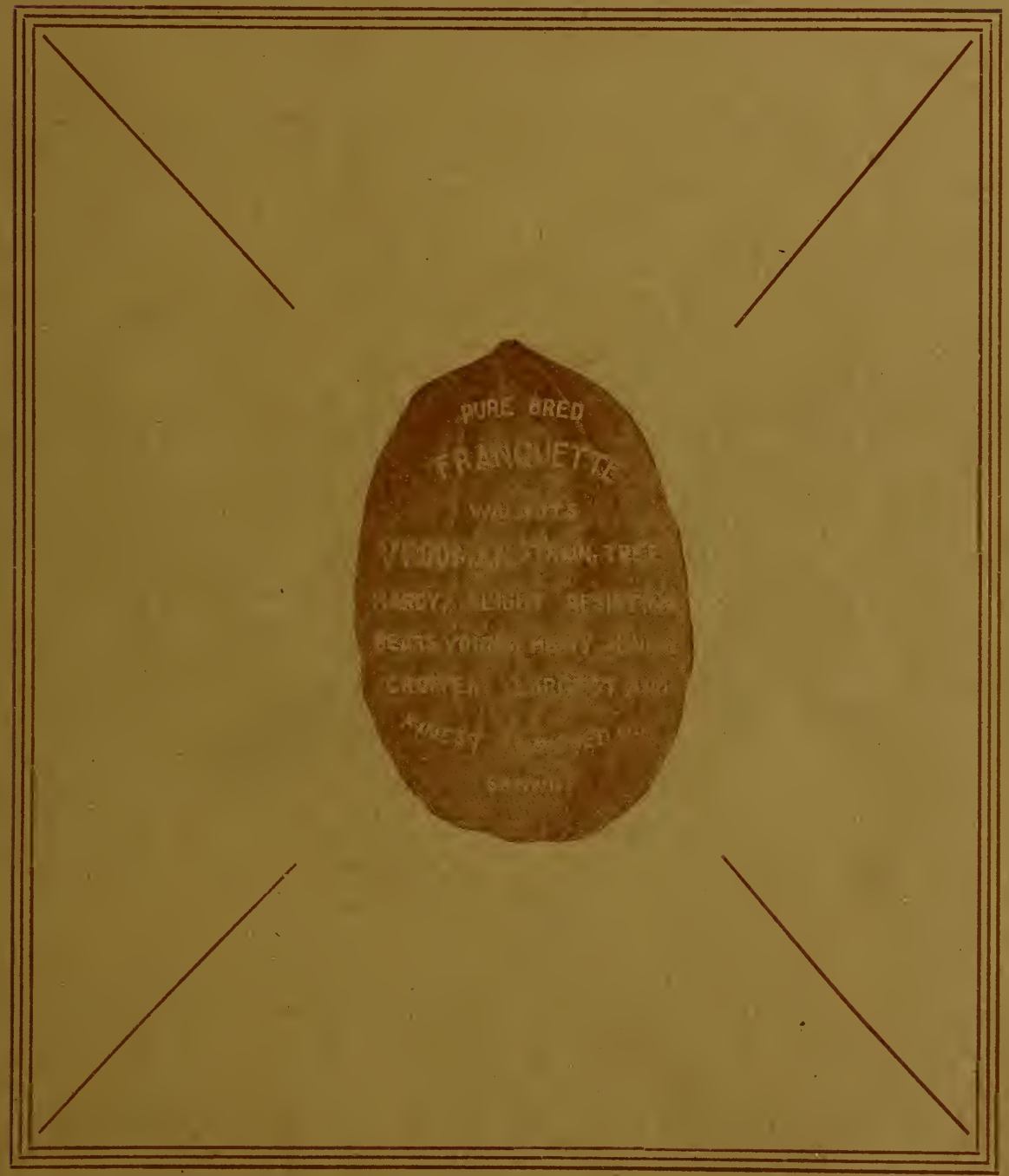

\section{OREGON NURSERY COMPANY ORENCO, OREGON}


7I "To the would-be walnut orchardist 4 we would say: Enter upon your task with enthusiasm, tireless vigilance and ready adaptability. There lies before you a possible and very profitable rich harvest of those joyful hours of pleasant labor well rewarded, and a harvest of golden ducats, and a strong, clear conscience that the world is the richer for your efforts." -MRS. E. M. VROOMAN. 


\section{Vrooman Pure Strain Franquette Walnut and Its Possibilities}

When You Plant Another Tree, Why Not Plant the Vrooman Franquette Walnut? Then Besides Sentiment, Shade and Leaves, You May Have a Perennial Supply of Nuts, Which Will Furnish You the Most Delicious, Nutritious and Healthful Food Which Has Ever Been Known.

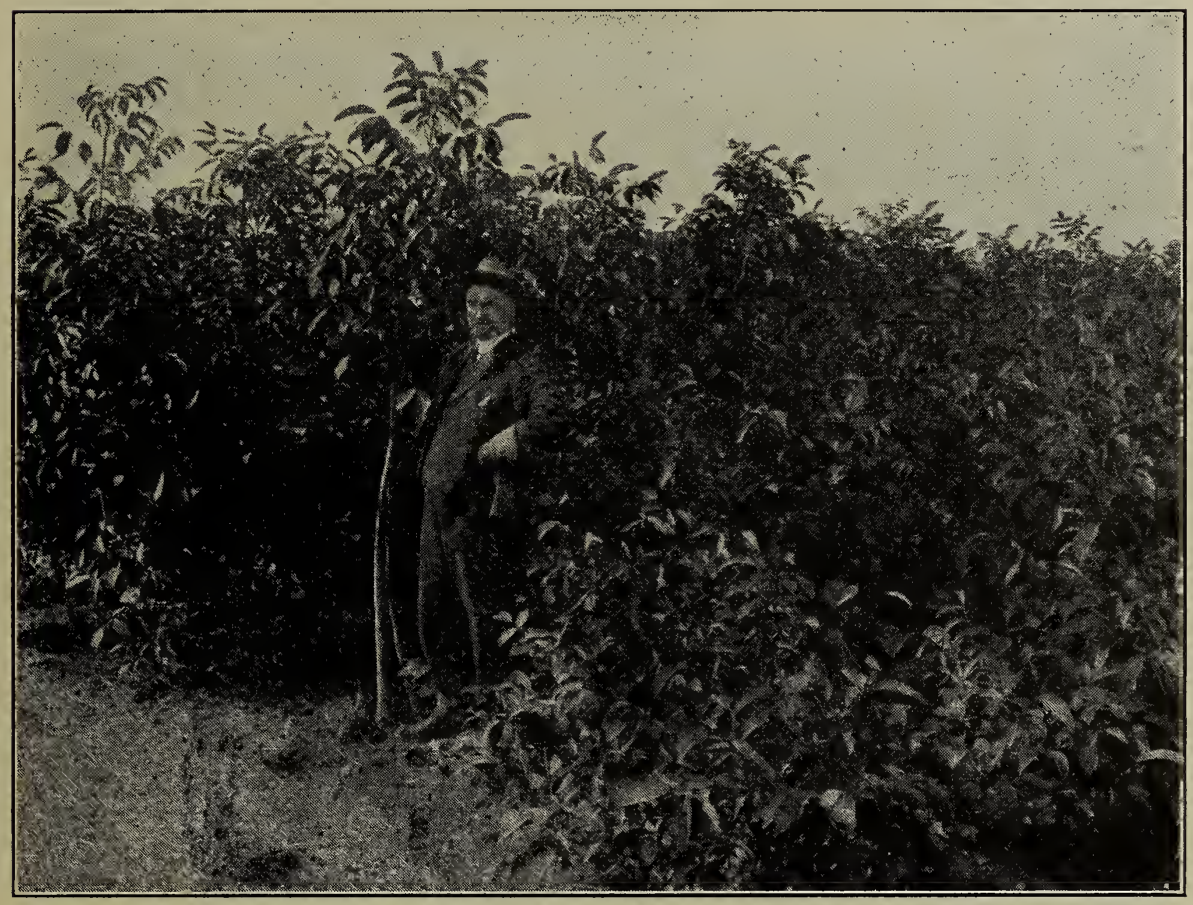

View of Vrooman Franquette Walnut block of trees in our nursery, indicating the size of trees we are prepared to deliver.

ROBABLY NO OTHER WALNUT, or for that matter any particular variety of fruit, has won such a prominent position in its class in so short a time as has the Vrooman Pure Strain Franquette. The walnut industry is one of such immense possibilities that we cannot hope to do it justice in this booklet, but shall endeavor to confine ourselves to a few of the important features as applicable to the Vrooman Franquette particularly. This splendid variety, which practically embodies all the essential qualities of a successful nut, particularly one suited for our more northern sections, is the result of proper selection and 


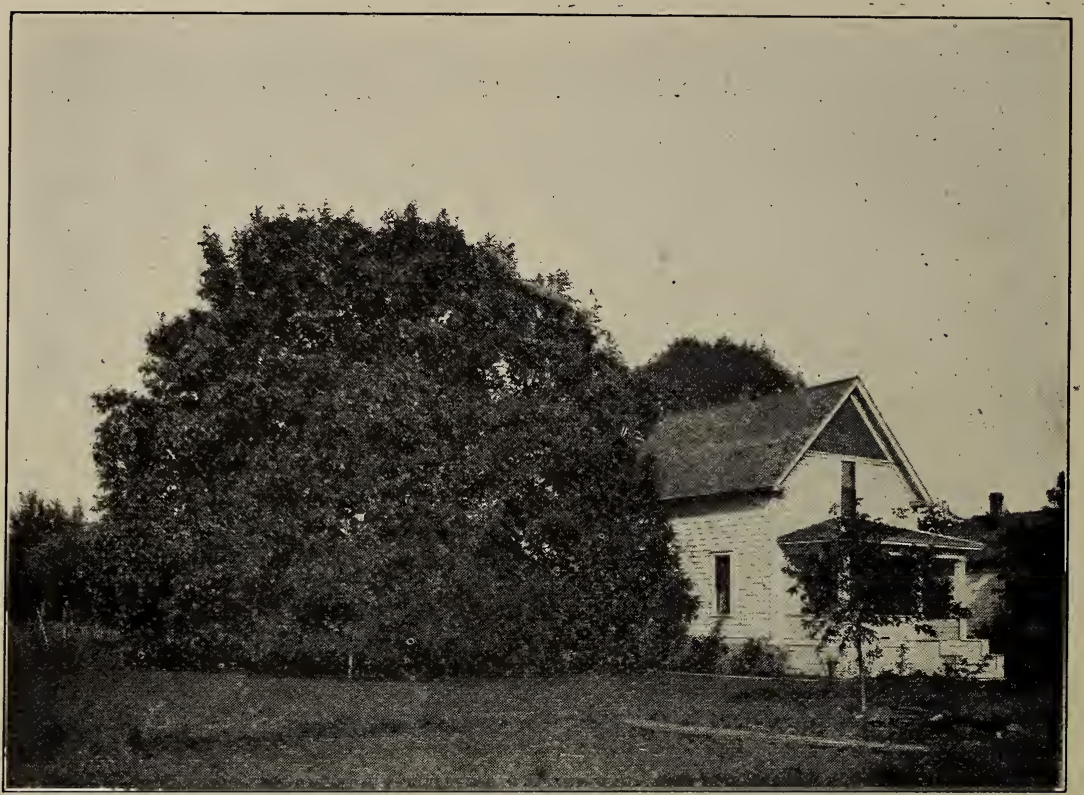

One of the largest Franquette trees in Salem, Oregon, belonging to Mrs. Nellie Knox, 1541 North Front street.

self-pollination, thus tending to unify the most desirable features of this good nut. The Vrooman Franquette has proven itself practically self-fertile, that is, it does not need to be planted with other varieties to make it bear nuts. In the Vrooman Franquette variety the unfavorable hybrid feature is eliminated. A hybrid nut is caused by the cross-pollination of two or more varieties, usually rendering the product unlike either parent. In the case of the Vrooman Franquette this does not exist, but trees of the same variety pollinate each other, thereby producing a pure strain Franquette nut or what some would term a thoroughbred. Trees grown from this stock can be relied upon to produce nuts of practically equal quálity, size and quantity as the parent trees.

\section{Investigation Reveals Pure Strain Franquette}

In the year 1905 the late Mr. Leon Girod, himself a practical nurseryman, was representing us in California, one of his duties being to carry on the walnut investigation we had started. The result was, after making a thorough survey of the country for either individual trees or a grove from which strictly dependable stock could be obtained for our propagations, he located a grove near Santa Rosa, California, which at that time was owned by the late Mrs. Emily Vrooman. This grove was most unusual in that it contained 1,000 trees all of one variety. All these trees were grafted from stock which could be traced directly back to the old Franquette tree in France, which is familiar to most nurserymen and horticulturists as one of the best bearing varieties known. Due to the fact that there are no other varieties than the Franquette in this thousand tree grove, 


\section{Producing a Large, Delicious, Nutritious? ${ }^{\mathrm{N}}$ ut}

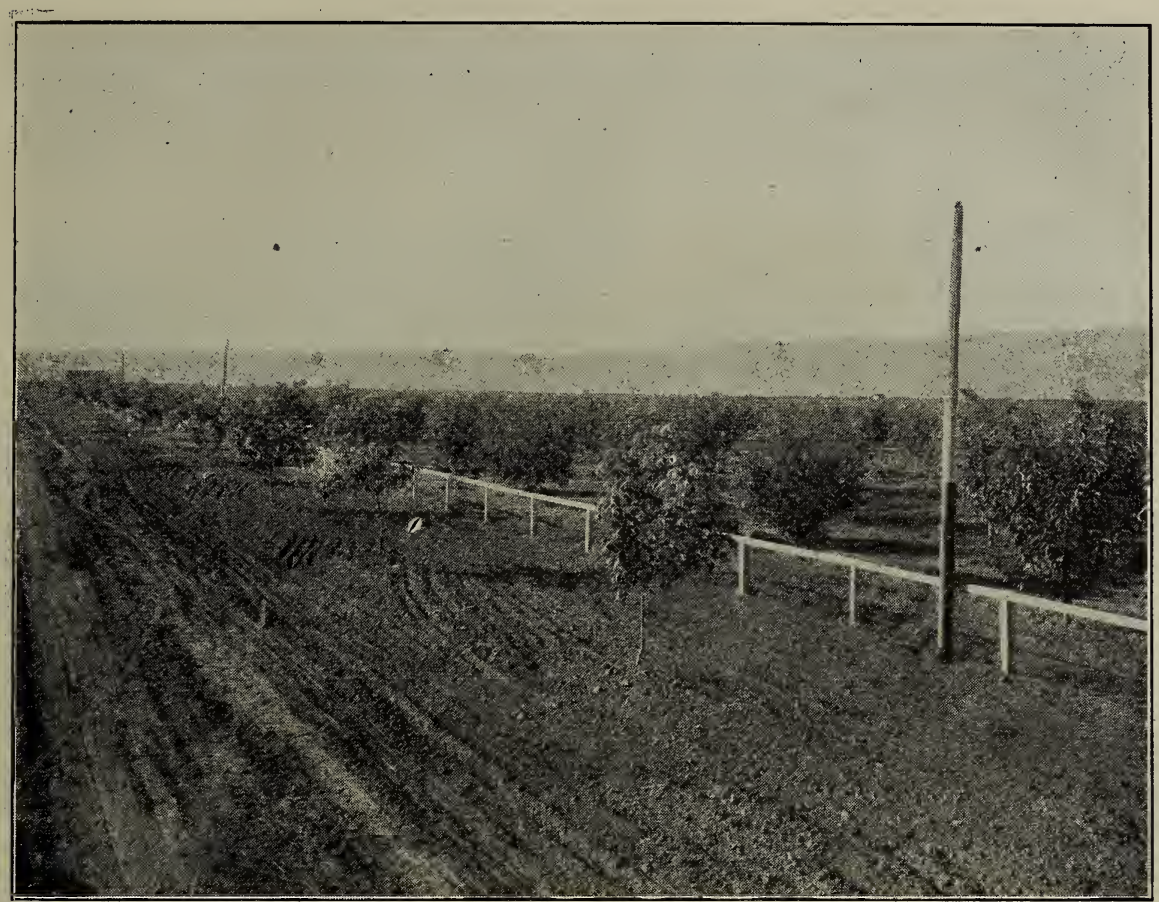

Showing Walnut trees planted along Burrell Avenue in the Lewiston Orchards, Lewiston, Idaho. These trees were planted in 1907; picture taken in 1910.

and there being no other varieties within a quarter of a mile of it, makes this orchard especially suited for producing propagating stock. Accordingly we entered into a contract with the owner to obtain the entire output of this orchard for a long term of years; thus we were assured of getting strictly reliable stock for our propagations.

\section{Gradually Increases in Favor and Popularity}

Time has proven that our expectations of the Vrooman Franquette were not misplaced, for every year has seen it gradually increase in favor and popularity - even in the face of well-known and established varieties-until now our nursery contains more walnuts than probably any other two or three nurseries combined, and the Vrooman Franquette leads all other varieties in the standpoint of demand.

\section{The Nut}

The meat of the Vrooman Franquette is generally conceded to be the most delicious walnut on the market. It is considerably larger than the average nut, a fair sample measuring from $1 \frac{3}{4}$ to 2 inches in length. The accompanying illustrations will give the reader a true conception of its size. The shell of this nut is medium in thickness, belonging neither to the hard or soft shell types. It is 


\section{Vrooman Franquette-A Hardy, Productive Tree}

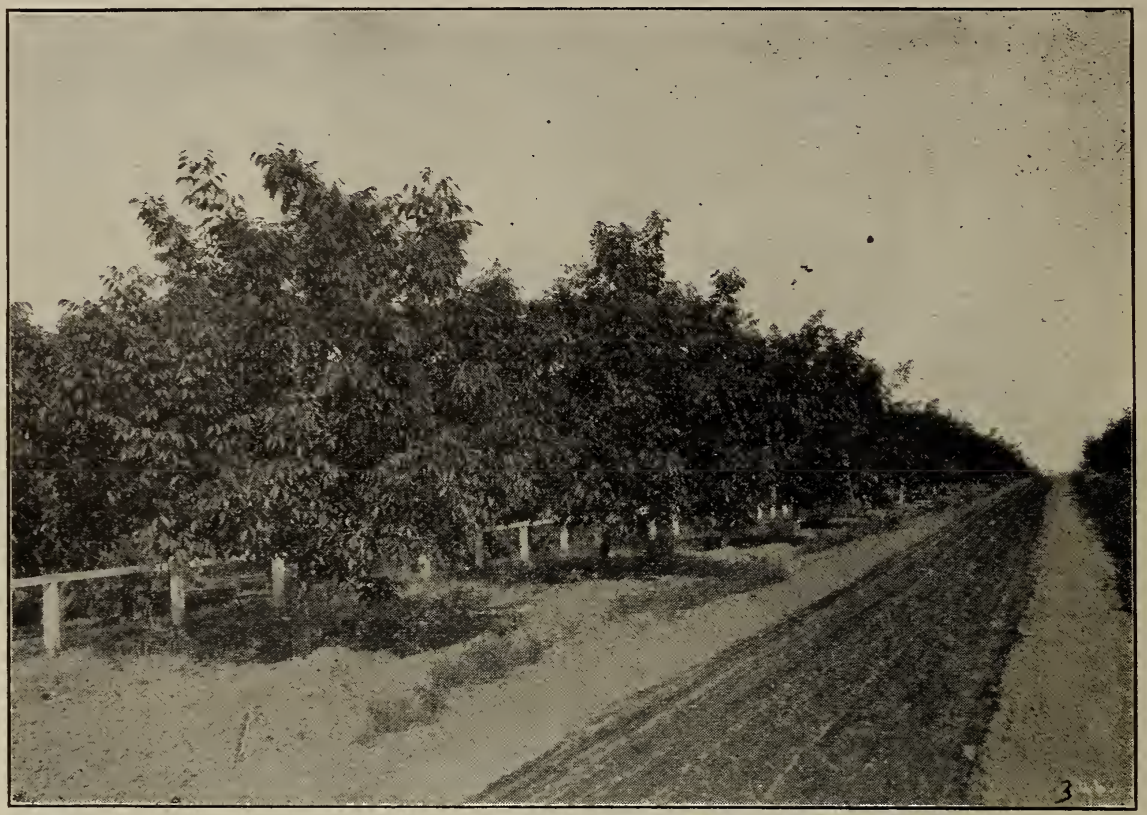

View of Walnut trees on Burrell Avenue, Lewiston, Idaho, same as shown on preceding page but taken three years later, 1913, from opposite direction.

unusually well sealed, making it an especially good commercial nut because of it standing the necessary handling, preparatory to marketing, without cracking open; which causes the kernel to dry out and lose all of its flavor. The kernel is unusually full of light colored meat, rich, sweet and of delicate flavor. The Vrooman Franquette demonstrates its superior qualities by finding a ready market at from 3 to 5 cents per pound above the average run of nuts.

\section{Vrooman Franquette Bears Young}

That the Vrooman Franquette is an early producer is amply illustrated in the following pages, showing photographs of trees in actual bearing as young as four years from transplanting. The following remarks by some well-known authorities may prove interesting to the reader. Colonel Henry E. Dosch, well known in Oregon as a horticultural authority, says, concerning walnut culture:

\section{Franquette More Hardier and Prolific}

"My first investigations of the walnut were rather discouraging on account of finding so many trees, then probably 20 years old, that were bearing no nuts. I concluded that there was something responsible for this condition not chargeable to our soil and climate, and learned that these trees were the most tender varieties growing in southern California and had been brought there by the Cath- . olic friars from Spain. Even there they are now discarded, owing to their irregular blooming. The staminate, or male blossom, appears several 


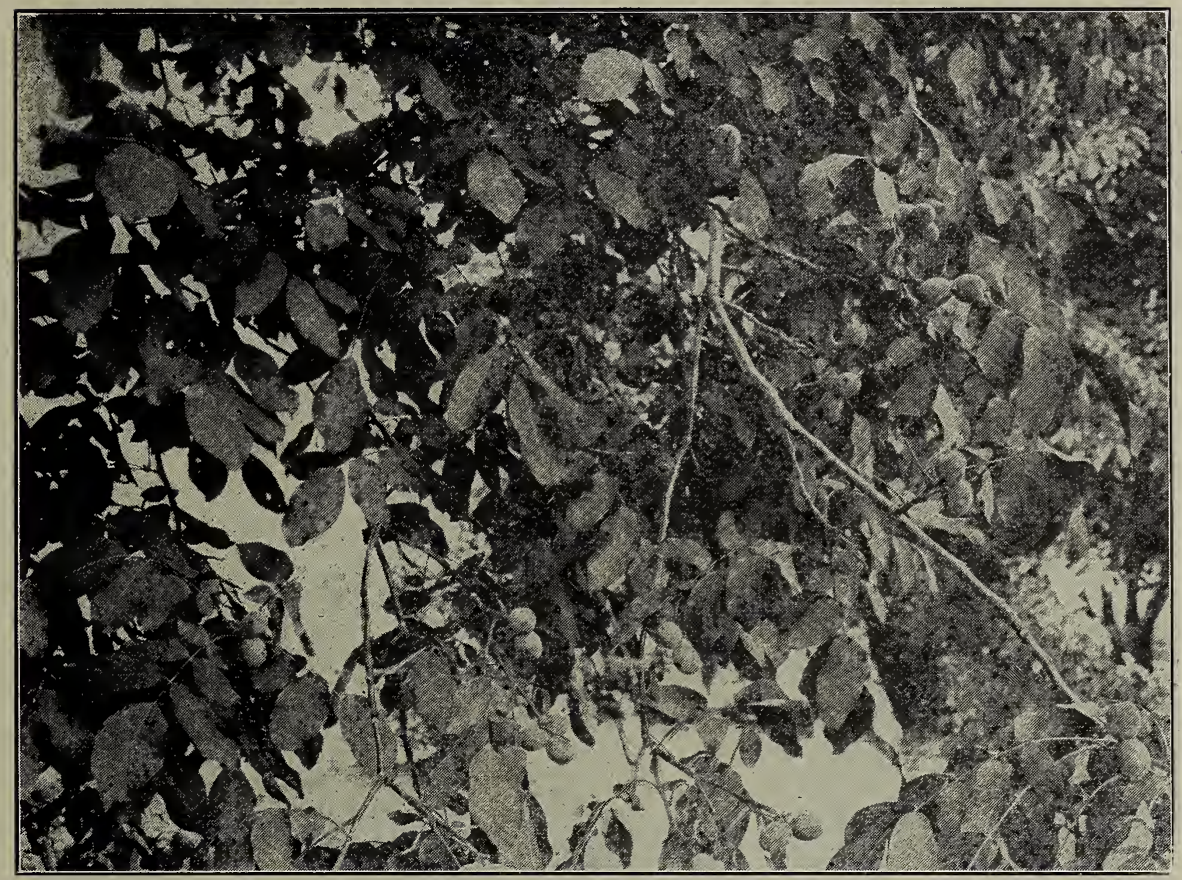

This shows the yield of one small branch of a Walnut tree belonging to Mr. Robert Schleicher, Lewiston, Idaho.

weeks ahead of the pistillate, or female blossom; hence no pollen and no nuts. This led me to investigate further, and I bought and planted a number of French varieties, including the Præparturien, Franquette, Mayette, Parisienne and Chaberte. Out of these. I finally selected the Franquette and Mayette as being best adapted to our soil, climate and market, giving preference to the Franquette, which I think is somewhat hardier, a more regular bloomer and a little more prolific.

\section{Adaptability of Our Various Soils}

"In order to thoroughly test the adaptability of the Franquette and Mayette to our various soils and sections, I gave away several hundred yearling trees, and have received most gratifying reports, whether planted on the Puget Sound, Columbia River Valley, Coast country, red hill lands, or on hollow lands in the Willamette Valley. However, in walnut growing three things are most essential and it is difficult to say which is most important, but they are Soil, Generation and Variety. While walnuts do well on all soil, even rocky soil, they are grateful to kind treatment when planted in a fairly rich soil, but there must be no hard-pan. The sub-soil must be loose and open so the roots can grow down as far as they desire, for as soon as they reach hard-pan the tree stops growing and of course this lessens the nut crop. 


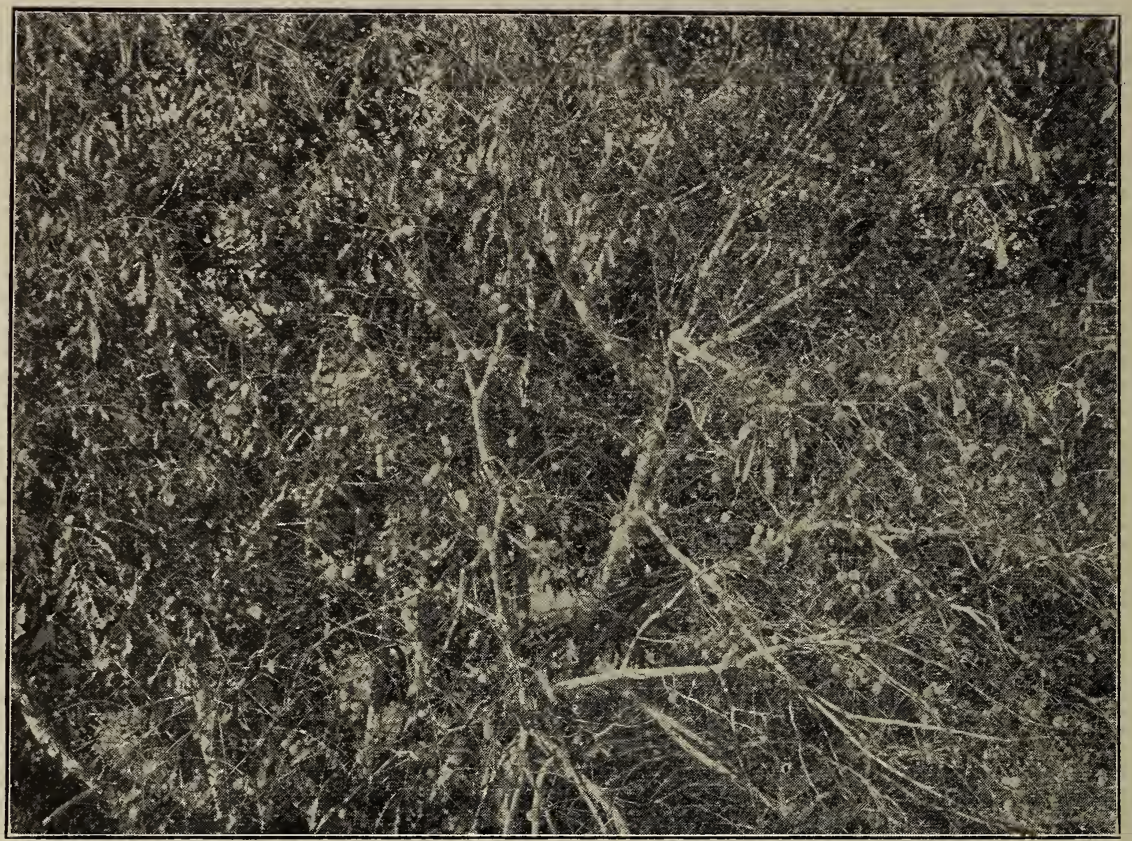

Showing:a section of a Walnut tree belonging to Robert Schleicher, Lewiston, Idaho. The absence of leaves caused by grasshoppers.

\section{Influence of Pollination}

"There has been considerable controversy about trees from first generation nuts bearing smaller nuts than grafted trees. I have not found it so, for I had as large and fine nuts on my trees grown from first generation seed as those from grafted trees; but also found that both kinds have some small nuts as well as large nuts; which led me again to study that point, and have reached the conclusion that the difference in size is due to pollination and starvation. When in the spring the pistillate blooms appear they usually come in pairs and generally are of equil size, until one of them forges ahead in growth and vigor by being better pollinated, and being stronger uses more nourishment, or in other words, the small one is starved out, making little growth and in consequence produces a smaller nut. It seems to be the law of Nature-the survival of the fittest.

\section{Walnut Growing Profitable}

"Walnut growing under favorable conditions is as profitable, if not more so, than any other branch of fruit raising, and as Oregon imports annually over $\$ 400,000.00$ worth of nuts, it seems a good business proposition."

\section{Vrooman Franquette a Hardy, Late Blooming Variety}

Judge Lieb, of San Jase, California, who has made a thorough study of 


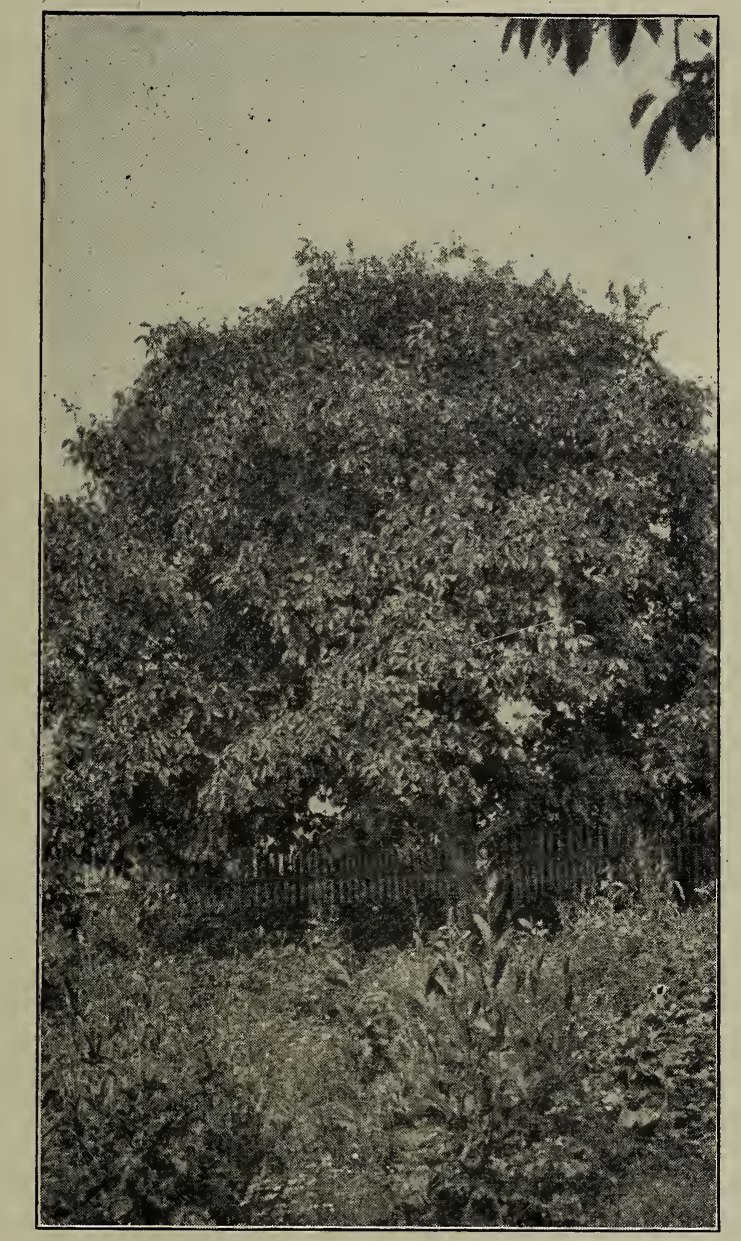

A profitable Walnut tree belonging to Thomas Brunk, Polk County, Oregon. Last year this tree bore 6 bushels of nuts, or equivalent to about $\$ 50$ worth.

walnuts in almost every condition, obtaining samples and particulars from many foreign and American growers, referring to varieties for Central and Northern California, says: "But two varieties need to be considered-the Franquette and the Mayette-but on account of the latter's tendency to start early in the spring, is not considered as profitable; whereas the Franquette, being a well-known late blooming variety, is to be preferred."

\section{Northern Sections Produce High-Grade Nuts}

The late Felix Gillet, of Nevada City, California, in one of his articles on 
walnut culture, said: "Walnut culture in the Willamette Valley, Oregon, has the advantage over nuts grown in Southern California in having a smooth, white shell without a prominent seam, while the meat is fat, the pellicle of a pale yellow, and the quality fine." To this might be added the fact that the extreme heat of some southern sections causes the nuts to sunburn, as well as injuring the tree. This results in the nuts having a bitter taste in place of the sweet, pleasant flavor found in the northern product. Naturally the remarks of Mr. Gillet would apply equally well to other northern sections as to the Willamette Valley in particular.

\section{Remarks of Prof. Ralph E. Smith, a Recognized Walnut Authority}

In Bulletin No. 231, published by the Agricultural Department of the University of California, Prof. Ralph E. Smith, plant pathologist and superintendent of Southern California Pathological Laboratory and Experiment Station, who is recognized as one of the best walnut authorities in California, among other things concerning the Franquette says:

\section{Franquette Recognized as a Standard}

"The Franquette is undoubtedly our best proven variety for Central and Northern California, and has one great advantage over any other variety for that section, that it has been thoroughly tested, and its merits and demerits well established. As regards quality of nut, this variety may be taken as a standard, as it is undoubtedly the best of any variety which has been widely tested in Caliifornia. Its characteristic and uniform shape, light, attractive color, both of shell and meat, firm sealing yet easy cracking quality, and the particularly pleas. ing flavor and consistency of the meat, all go to make the Franquette nut one of the very highest quality.

"The variety is also strong in freedom from blight and spring frost injury, on account of its very late season of coming out. The thick husk and abundant foliage protect the nuts from sunburn to a very large extent, and the variety is not especially susceptible to any other trouble.

"Franquette nuts have commonly sold for nearly twice the price of California seedlings.

\section{Oregon Nursery Company Recognizes Superior Merit}

"The present standing of the Franquette as the leading Northern California and Oregon variety is based on the success of the Vrooman grove at Santa Rosa. This sixty-acre walnut orchard was planted by the late Mrs. Emily Vrooman at a time when walnut growing north of Santa Barbara county was absolutely unknown, and as a result of Mrs. Vrooman's investigations of and confidence in the Franquette, the quality of this variety is well established. Through the influence of the Oregon Nursery Company, who bought the scions and nuts from the Vrooman orchard for a period of several years, the fame and popularity of the Franquette is largely extended, and many others have become familiar with and planted the Franquette on a considerable scale, both in Central and Northern California and Oregon."

Concerning the flavor Prof. Smith says: "It is sweet and free from bitterness, with a characteristic nutty flavor, approaching that of a hickory nut. The consistency of the meat is also characteristic, being soft, or oily." 


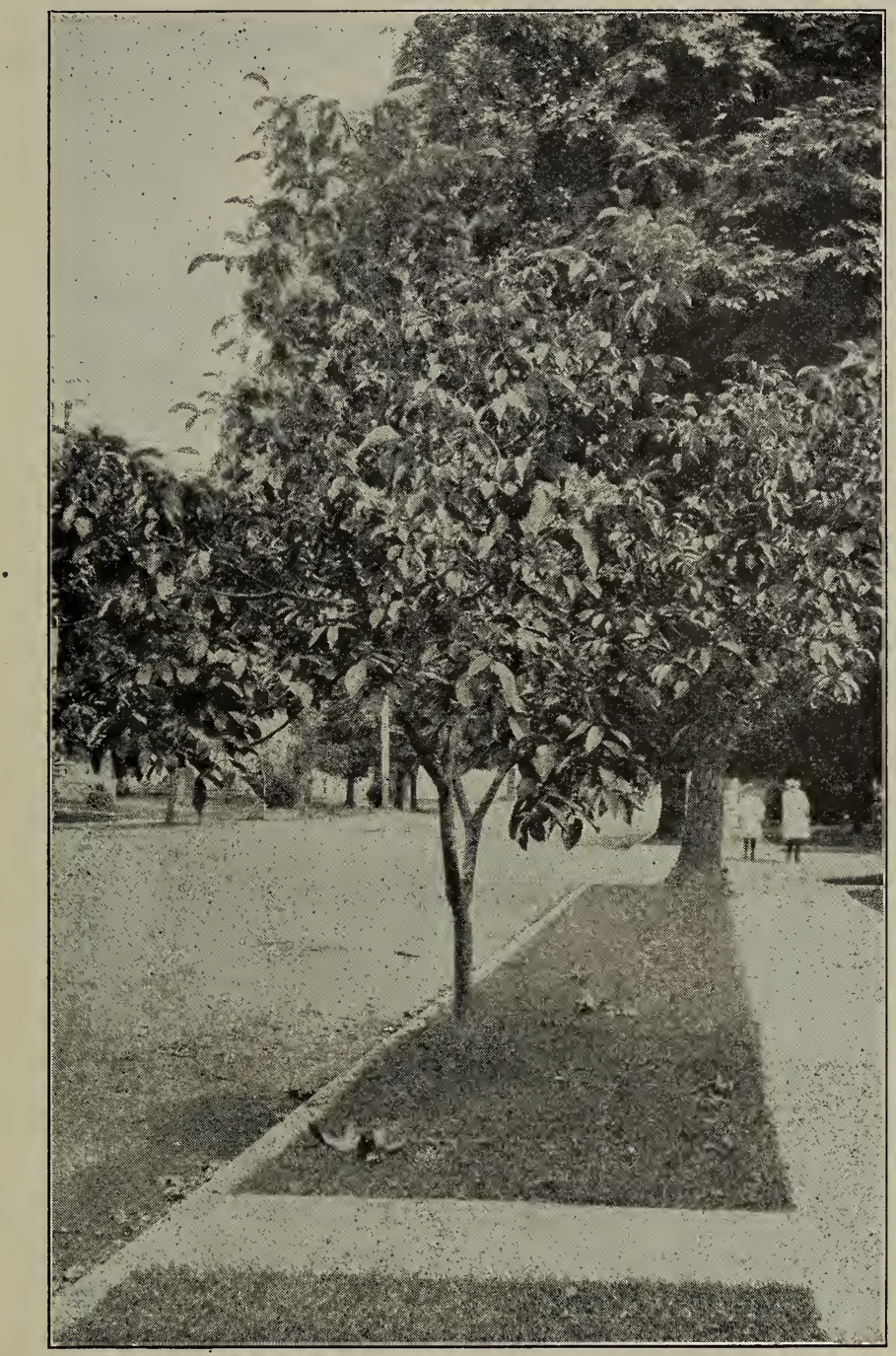

This is a Franquette Walnut tree, four years from transplanting, on Ferry street between Sixth and Seventh, Albany, Ore. Note the splendid yield of this young tree. There is no more desirable tree for planting on your curb or in your front or back yard, than the Vrooman Franquette Walnut.

\section{Possibilities of Walnut Culture}

Much might be said on this point. When one takes into consideration, however, that in the year 1909, according to statistics compiled by the United States Department of Commerce and Labor, there were 26,157,000 pounds of walnuts, valued at over $\$ 2,250,000$, imported into this country, and that in 1912 the importations had increased to over $37,000,000$ pounds, valued at over $\$ 4$,- 
000,000 -we get a fair idea as to the immense market there is for good walnuts in this country, and if you have ever compared imported nuts with home grown nuts you will appreciate that the home grown product is of a very much better grade and higher quality. As Dr. Walgamot, in his letter on Page 12, states that some of the leading merchants of Portland told him that they sold twelve times as many walnuts as all other kinds of nuts combined, shows conclusively that there is a demand already existing for this product.

\section{Regular and Reasonable Profits}

It is claimed by some of the largest walnut growers in Southern California that some of their individual trees produce as high as $\$ 40$ worth of nuts per year, while the general average is between $\$ 20$ and $\$ 25$ per tree. Figuring 27 trees to the acre-which is the number required if set 40 feet apart-it means at least $\$ 540$ to $\$ 675$ per acre. From the little attention required by walnut trees they have been termed the "Lazy Man's Orchard." It is much as Mr. Foss says in his letter on Page 23: "It is not the selling price we are so much after as it is the amount left after all expenses are paid." Considering the fact that walnuts are probably the most easily handled orchard crop to be had, the net returns per acre will compare most favorably with any other line.

\section{WELL PLEASED WITH THE WALNUT TREES.}

"Your favor of the 3rd just received. I am well pleased with the walnut trees you shipped me this fall, also the peach trees that came with them. I believe the walnut will do as well here in the hills as any fruit and walnut trees the size I received will grow easily and quickly. You may refer any one to me you wish to."-W. J. Cameron, Derby, Ore., Dec. 9, 1913.

\section{A BANKER'S OPINION-}

"I am pleased to be able to say in regard to the Vrooman Franquette Walnut trees ordered of you, that the trees were delivered in the very best of condition about the first of this month. The stock exceede $a^{2}$ my expectations in size and appearance. Further, I desire to express my highest appreciation of the treatment I have received at your hands-your prompt and cordial attention to my order and the manner in which and the character of the stock with which it was filled.

"While my experience with the walnut has been very limited, yet I share with you the optimistic view of the possibilities of this enterprise. I am interested in the success of your effort to secure for it the recognition it deserves, and shall be pleased to be helpful to you in any way possible in the furtherance of the undertaking.

"My trees are planted in good form and in what we think is a most favorable location. We are very hopeful of the best results here and will doubtless be in the market for another shipment of this same class of stock next year. Kindly keep me on your list.

"Please accept my most cordial thanks for the dozen special trees delivered to me by your agent here.

"Please be free to refer to ine in any case where I may be of service to you."'-W. H. Gore, Medford, Ore., Dec. 17, 1913.

(Mr. Gore is president of the Medford National Bank.) 


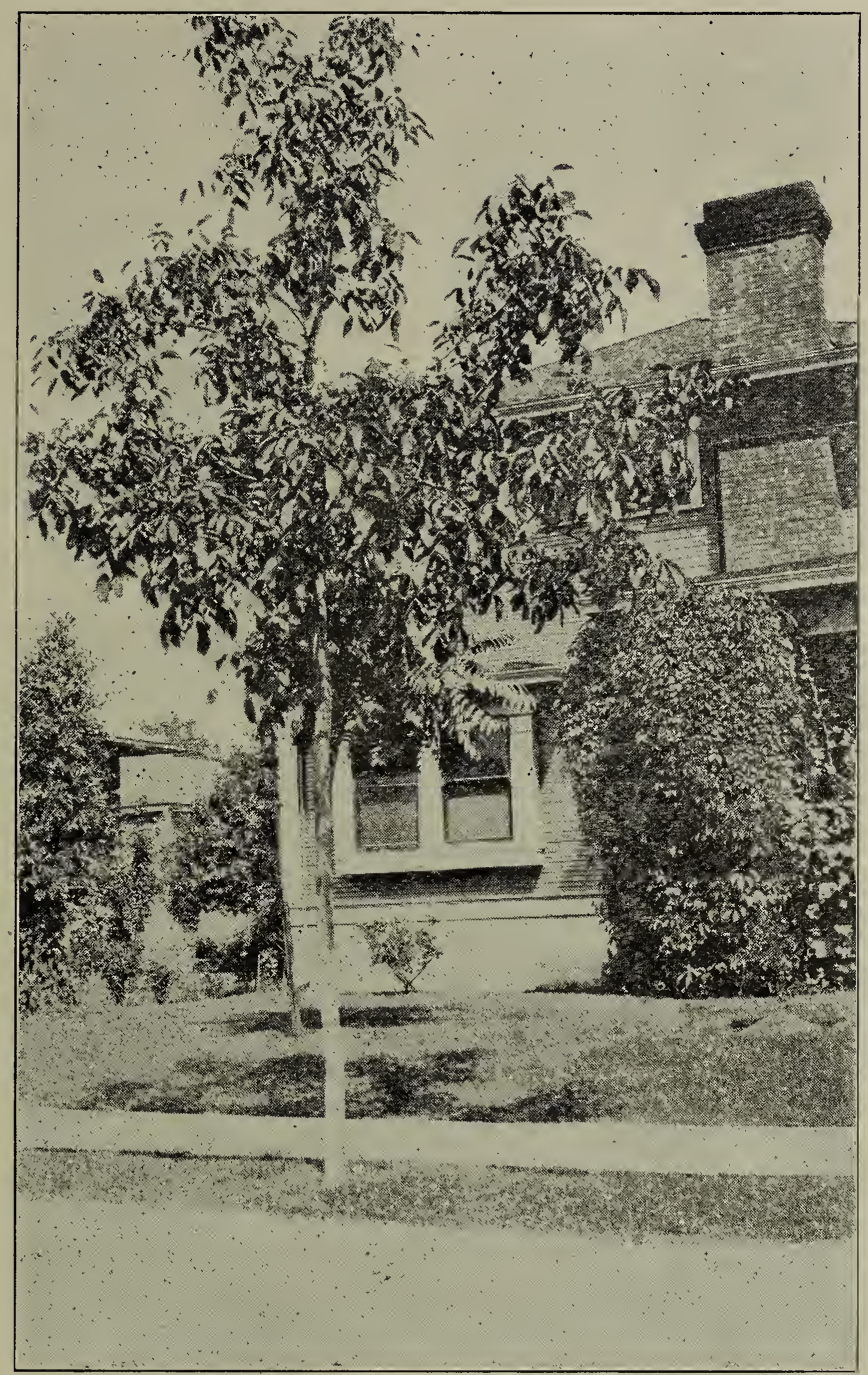

A 4-year-old Vrooman Franquette Walnut belonging to L. E. Blaine, of Albany, Ore., which is estimated to have a half bushel of nuts on it.

\section{SINGLE WALNUT TREE PRODUCES \$70 WORTH OF NUTS.}

Juliaette, Ida., Oct. 19, 1913.

"Right in the heart of Juliaette this season 280 pounds of walnuts were gathered from a single tree. The ground has never been cultivated and the tree has grown in cramped quarters. At 25 cents per pound this tree produced a crop worth $\$ 70$. One of our salesmen, who is familiar with this tree, advises that it is undoubtedly of the Franquette variety, as the tree has the characteristics and

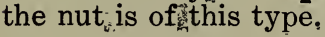



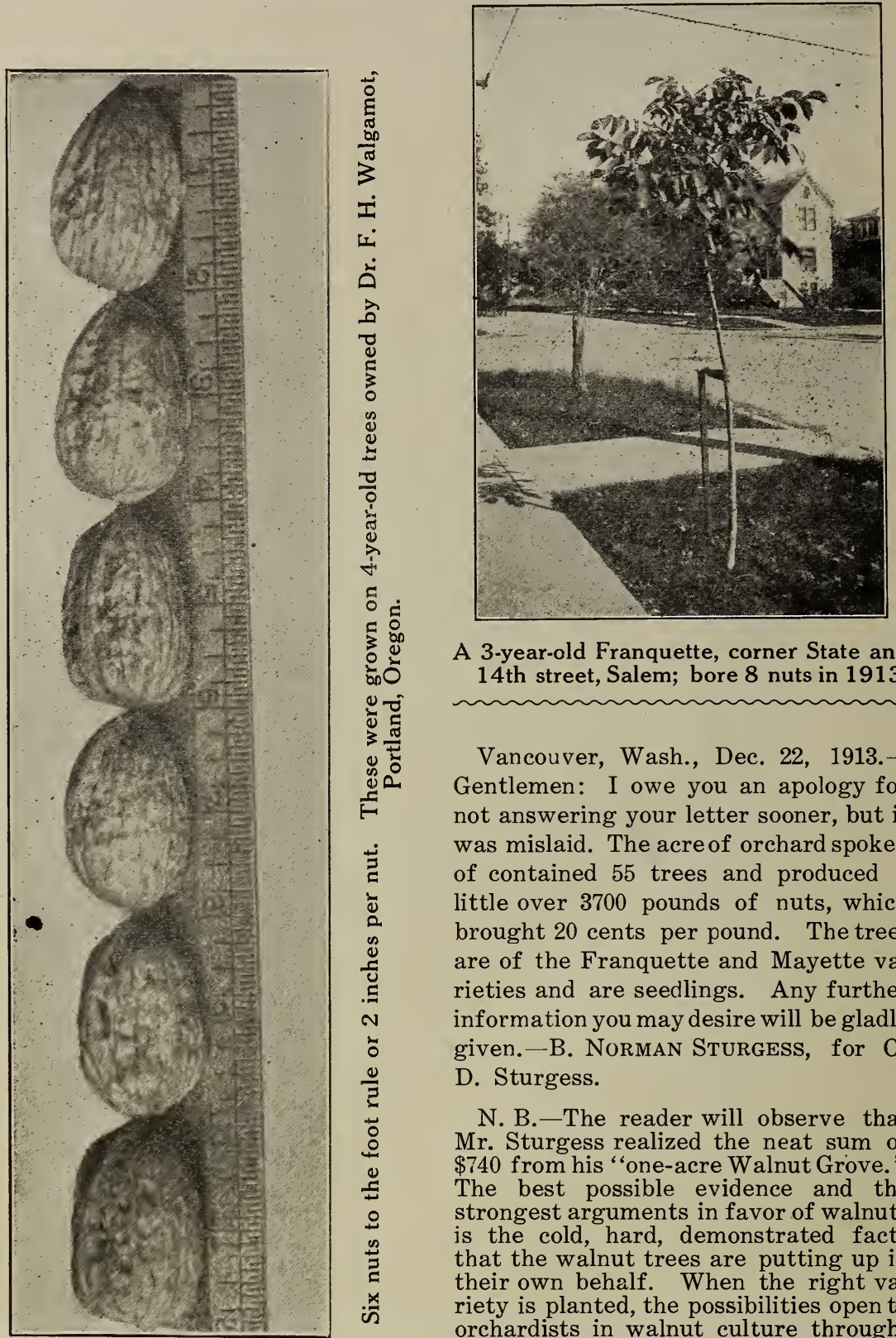

A 3-year-old Franquette, corner State and 14 th street, Salem; bore 8 nuts in 1913.

Vancouver, Wash., Dec. 22, 1913.Gentlemen: I owe you an apology for not answering your letter sooner, but it was mislaid. The acre of orchard spoken of contained 55 trees and produced a little over 3700 pounds of nuts, which brought 20 cents per pound. The trees are of the Franquette and Mayette varieties and are seedlings. Any further information you may desire will be gladly given.-B. Norman STURGESS, for O. D. Sturgess.

N. B.-The reader will observe that Mr. Sturgess realized the neat sum of $\$ 740$ from his "one-acre Walnut Grove." The best possible evidence and the strongest arguments in favor of walnuts is the cold, hard, demonstrated facts that the walnut trees are putting up in their own behalf. When the right variety is planted, the possibilities open to orchardists in walnut culture throughout the entire Western states is beyond the fond dreams of the most optimistic.

"One Walnut tree at the home of C. H. Lew, Escondido, California, is reported to have produced 275 pounds of nuts last year."-Pacific Rural Press. 


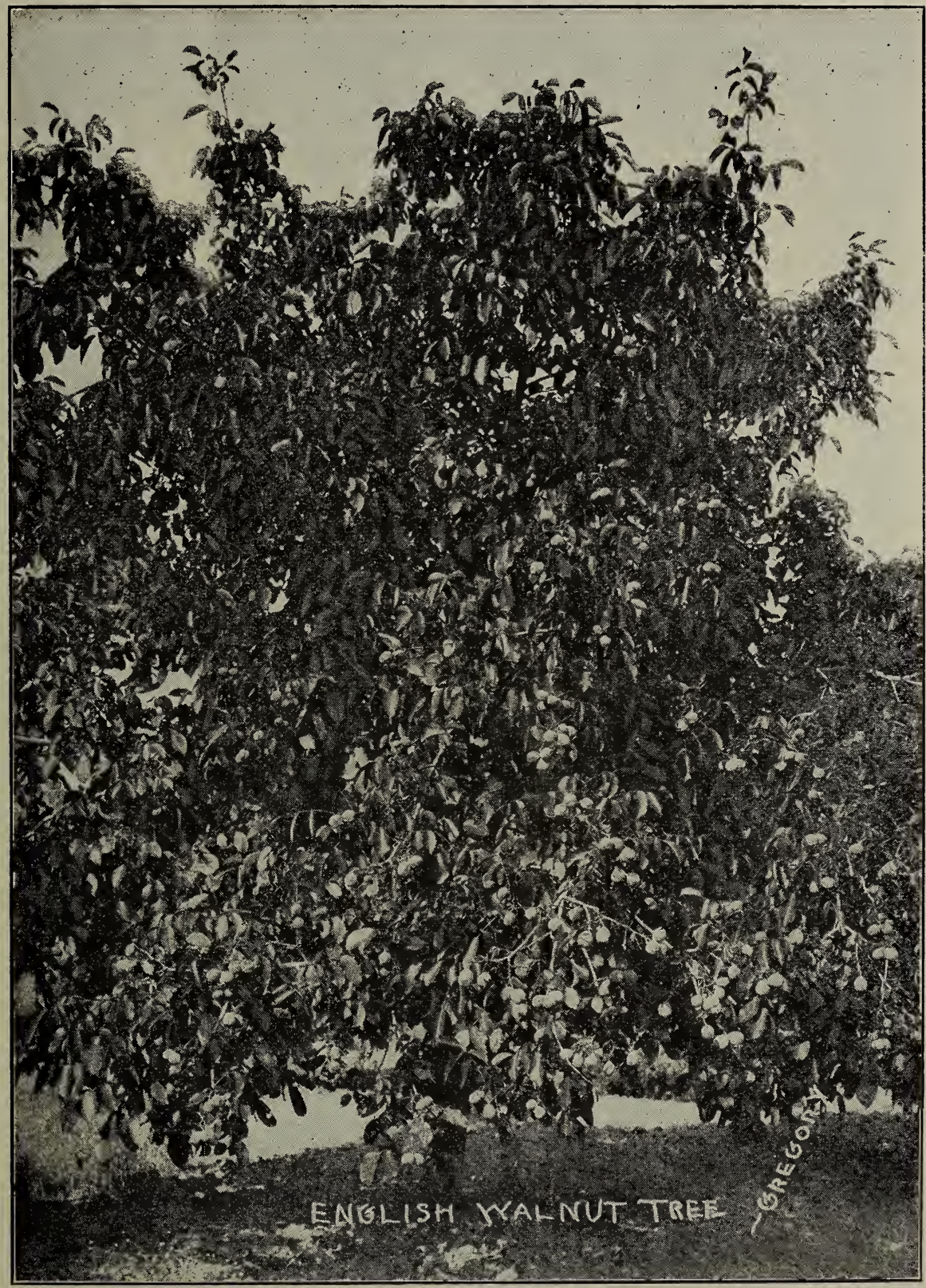

Walnut tree on the property of Dr. E. P. Geary, Medford, Ore. Dr. Geary says: "My walnut grove is almost an accident ${ }_{*} *_{*}$ they grew in spite of all kinds of neglect. We never took the walnut very seriously until we found many more nuts than we could use, and last year had $\$ 100.00$ worth to sell. I think the walnut tree is ideal for beauty and profit on any farm or dooryard on which it will grow." 


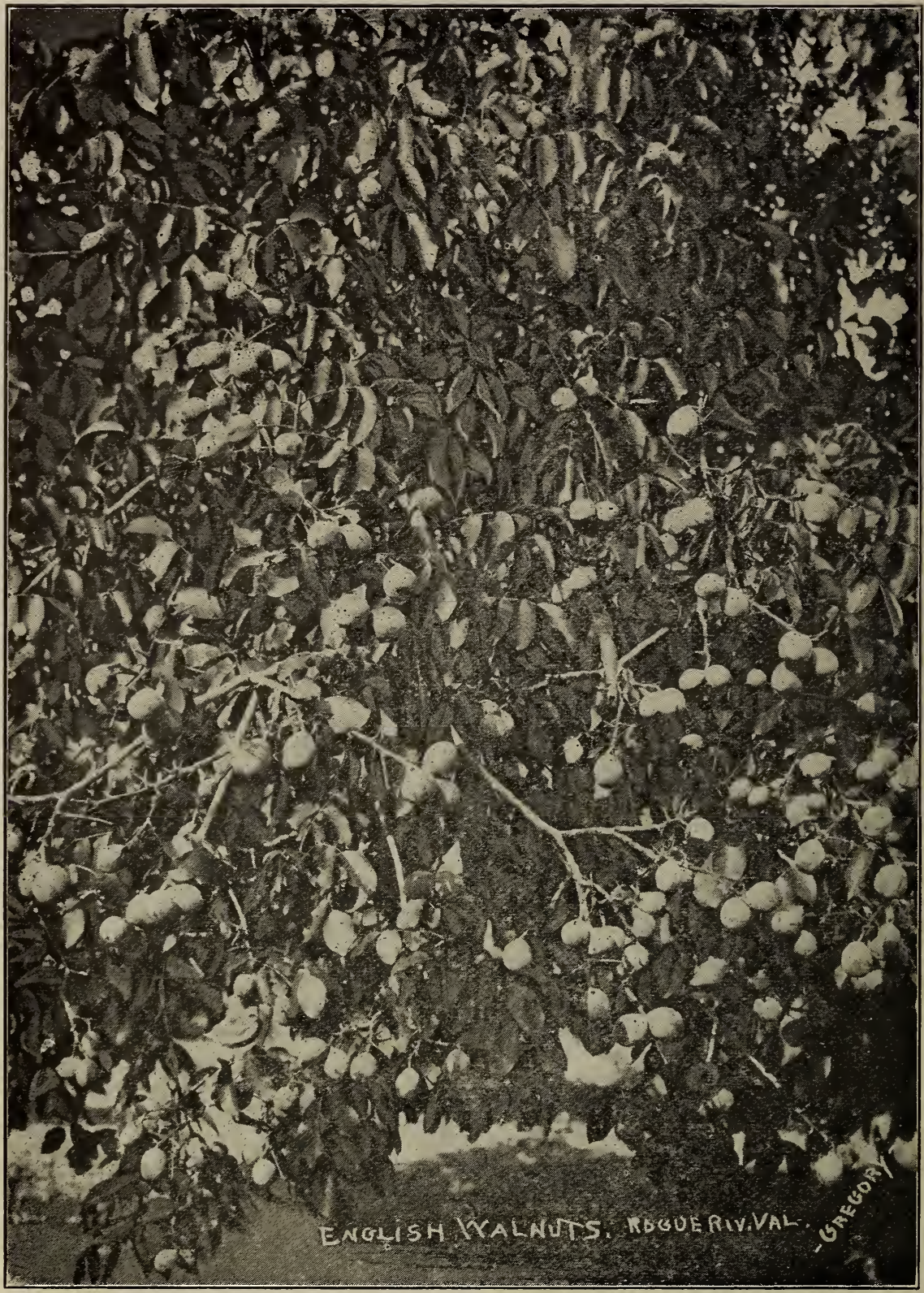

This shows a portion of the walnut tree.in the previous illustration belonging to Dr. Geary at close range. How would you like to have several walnut trees bearing like this one? 


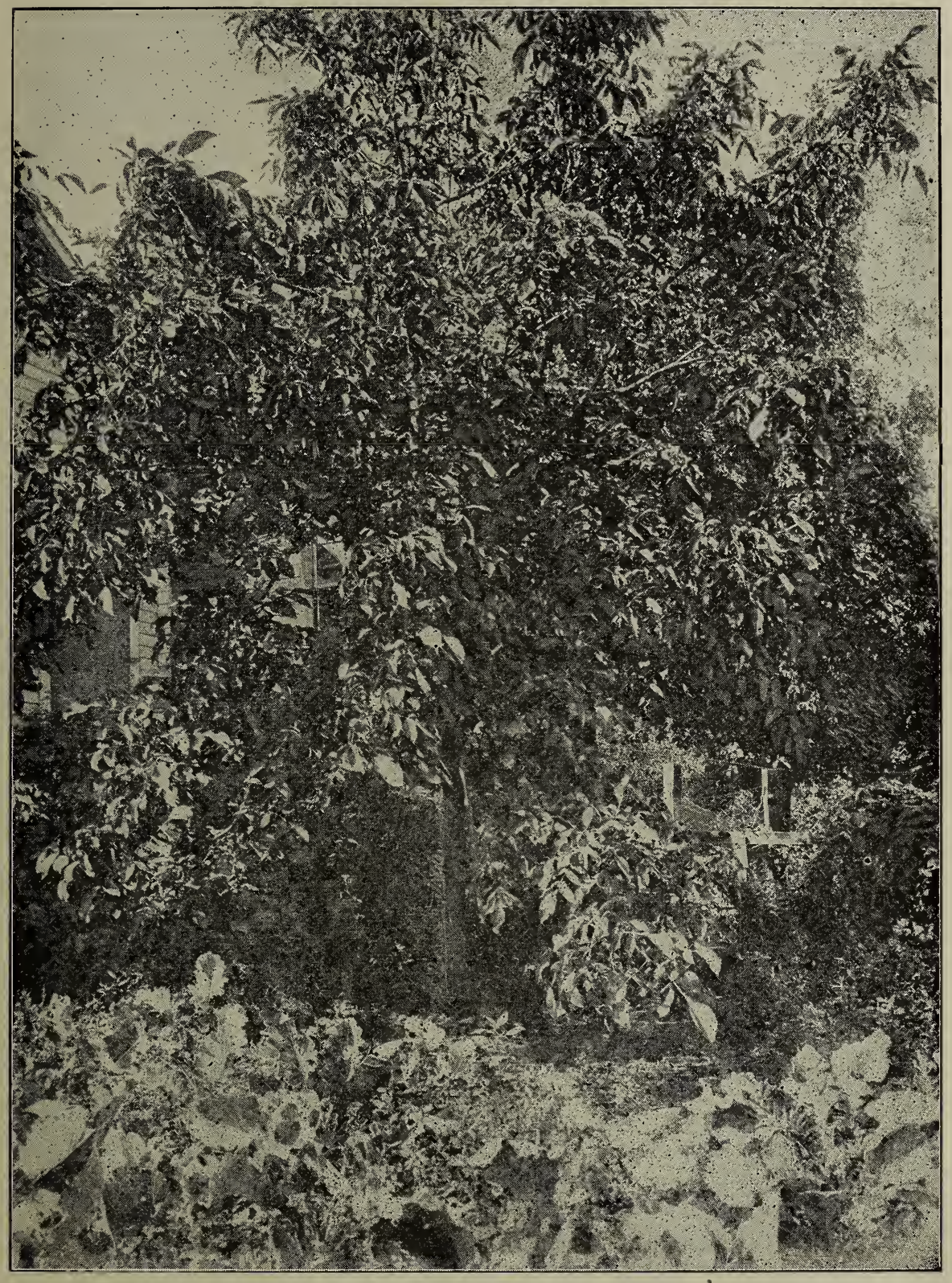

Franquette Walnut belonging to Mr. John Spurgeon, Clarke county, Washington. Observe the lower limbs weighted with their burden of nuts.

"For the last six years my 23-year-old Walnut tree averaged about 200 pounds of nuts per year."--Mrs. W. R. KIRK, Brownsville, Oregon. 


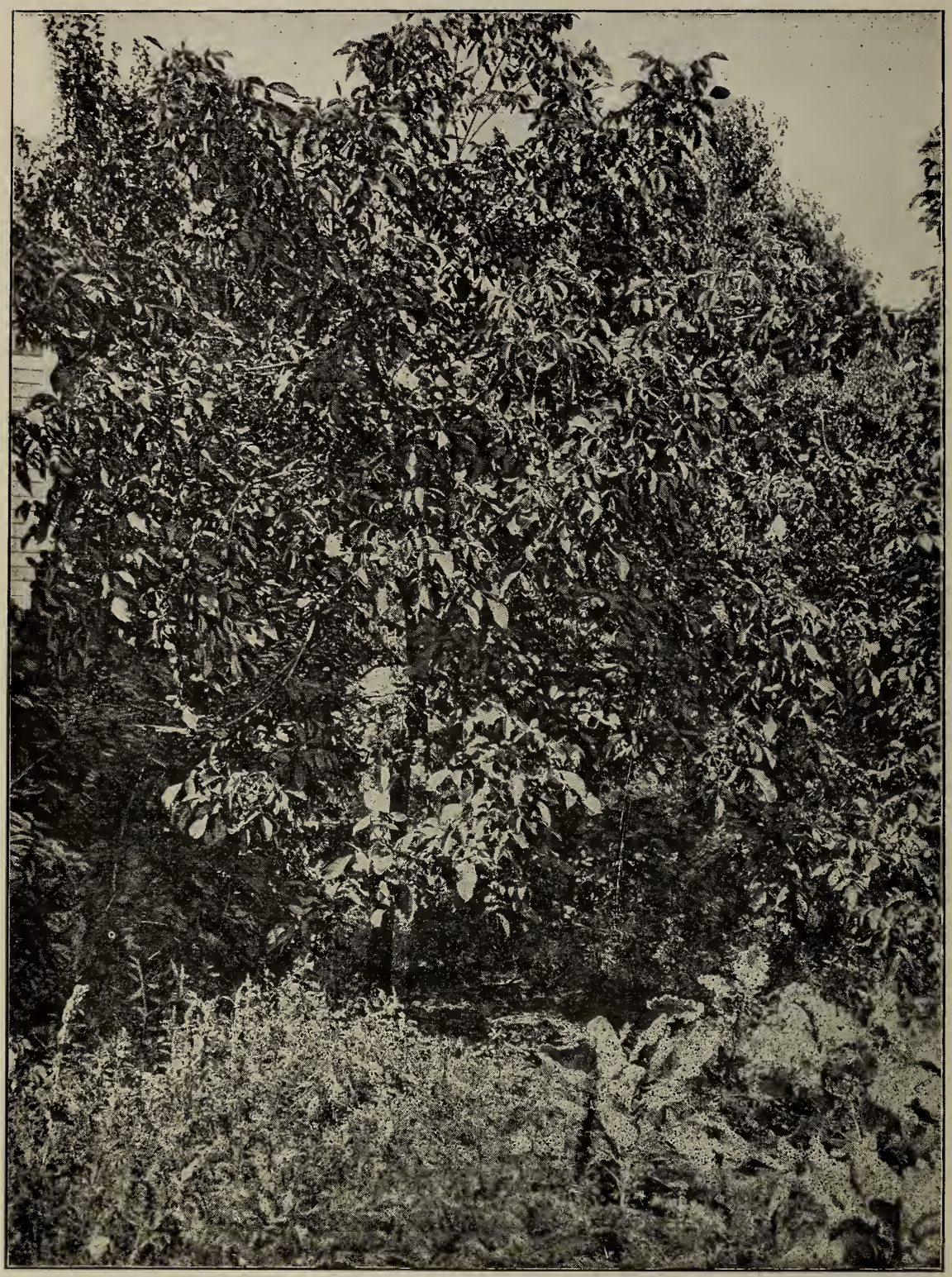

This is another heavy bearing Walnut tree owned by Mr. John Spurgeon, fruit grower, Clarke county, Washington.

"The Franquette Walnuts I bought of you last Spring have done fine. They were planted June 1st, and have now made a growth of two feet."-MichaEL KoNNI, Peck, Idaho. 


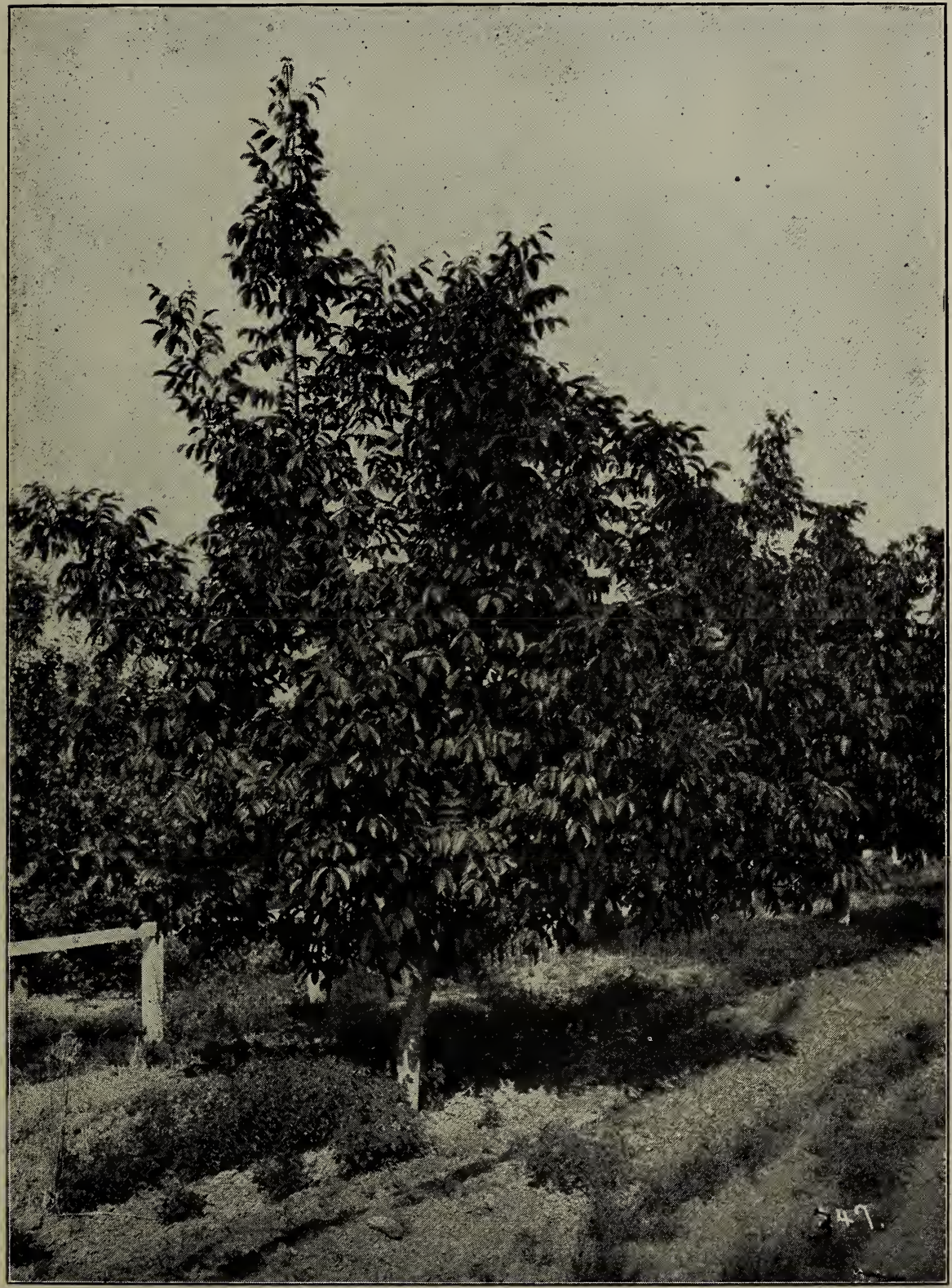

A 6-year-old walnutĩ tree, Lewiston, Idaho, bearing its first delicious nuts this year.

"I have four different varieties of Walnut trees in bearing, and can say that my Franquette is by far the best that I have. It blooms later, yields more nuts and I get 3 cents per pound more for them than for other varieties."'-H. MEHLANN, San Luis Obispo, California. 


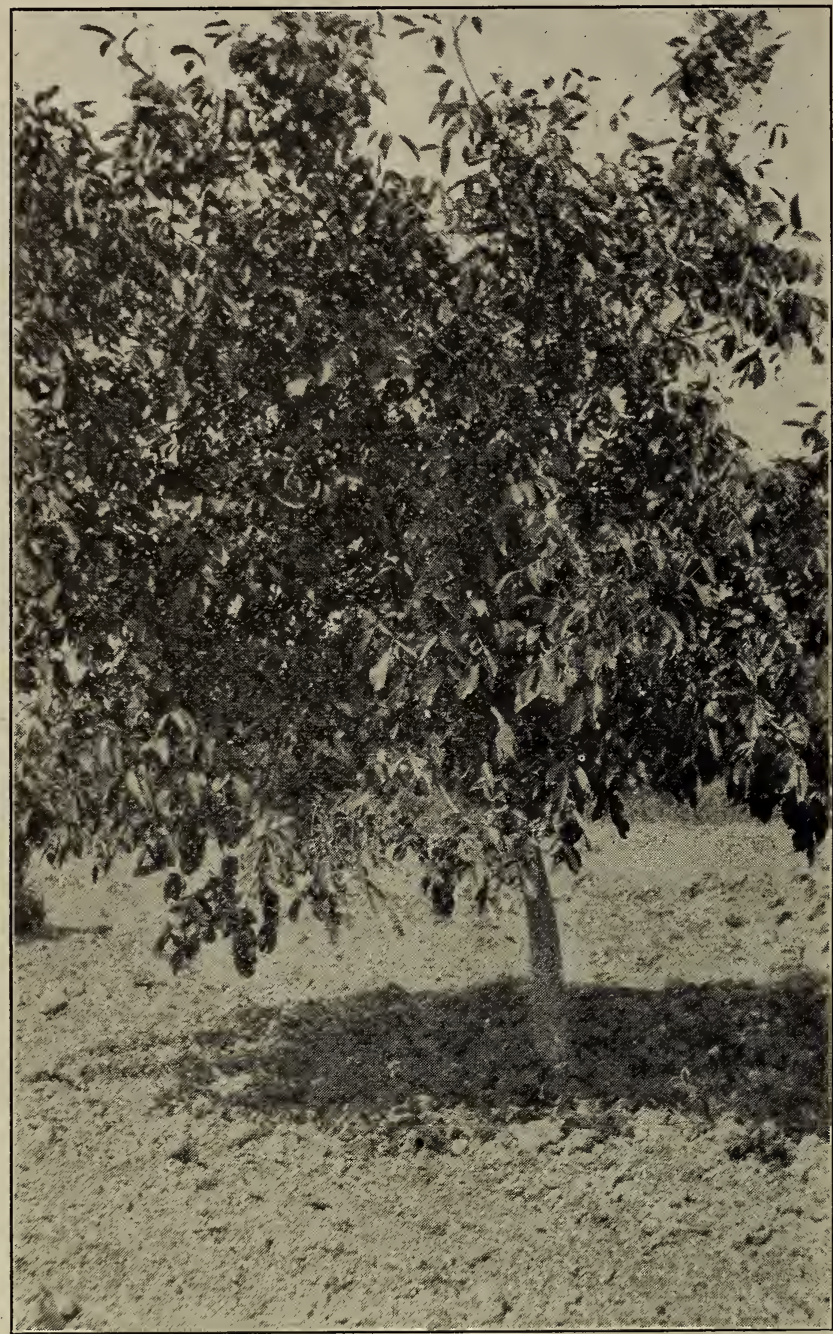

Another sample of prolific Walnut trees which are to be found almost any place through the Willamette Valley and tributary sections.

"I am confident the Walnut industry is to become one of the important horticultural industries of Oregon. Walnut growing appeals especially to conservative persons who are looking for an industry which permits regular and reasonable profits. I believe that those who use good judgment in the selection of site, soil and trees, will obtain as good net returns upon their investment as can be obtained in any branch of the fruit business, and that the net returns will come more regularly from Walnuts than from almost any other horticultural product." -H. M. Williamson, Henry Building, Portland, Oregon. 


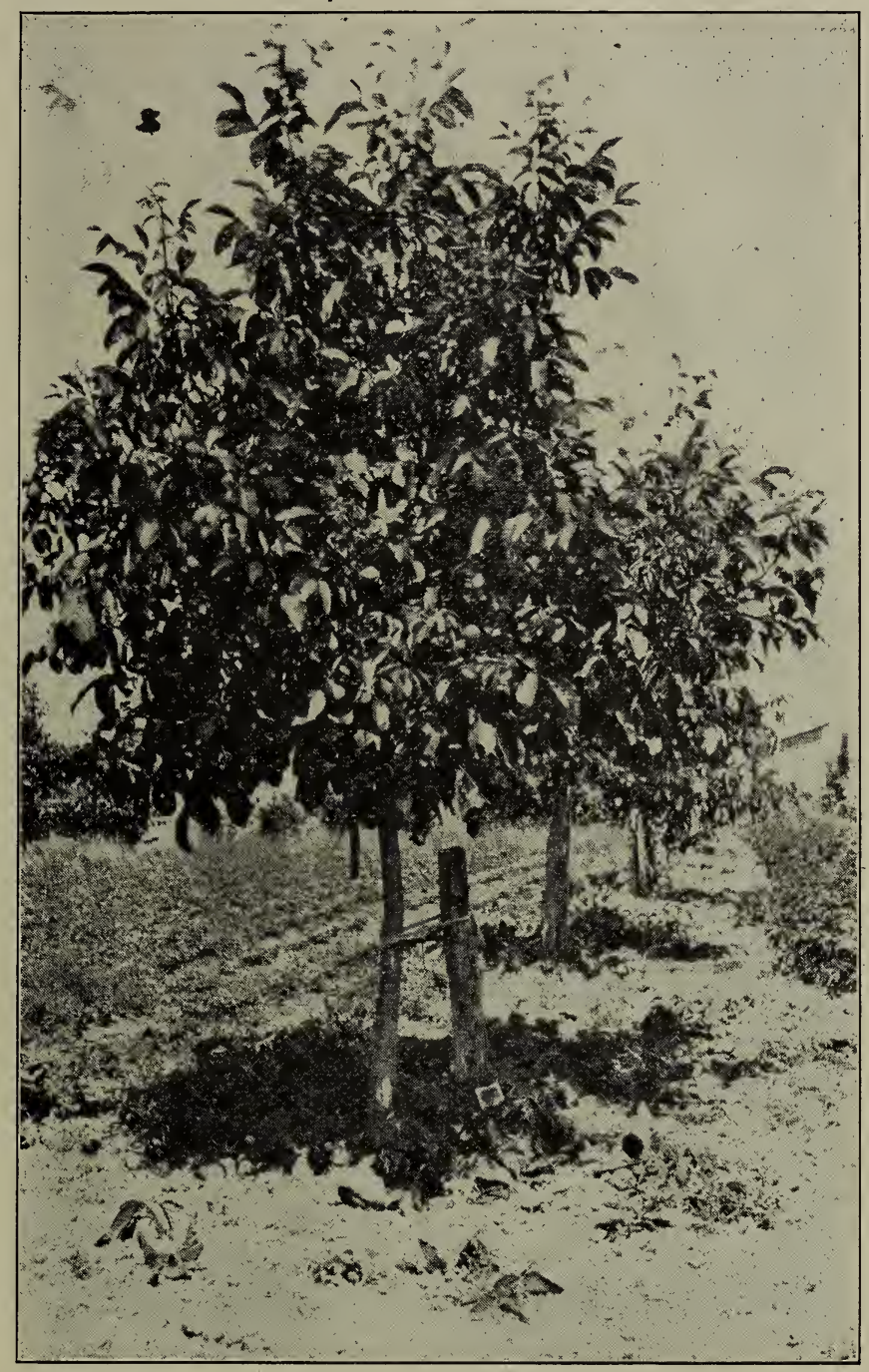

A Franquette Walnut in the vicinity of Albany, Ore., showing its early bearing proclivities. This tree is $\mathbf{5}$ years old from transplanting.

“My first walnut trees were planted about 23 years ago, they were 3 year olds and began bearing the third- year after planting; the others were yearling trees planted about twenty years ago and began bearing the fourth year after planting. One seedling tree is nearly if not quite 40 feet high and is covered every year with nuts, but of small size, the other trees are trained low. As to yield there are too many children, squirrels and Blue Jays, saying nothing of men, who are interested in walnuts, so that the crop when gathered does not represent the whole yield by any means; nevertheless, I get several sacks of nuts. The yield is quite even, last year was the only one when I had a short crop.-Henry HeWETt, Portland, Oregon. 


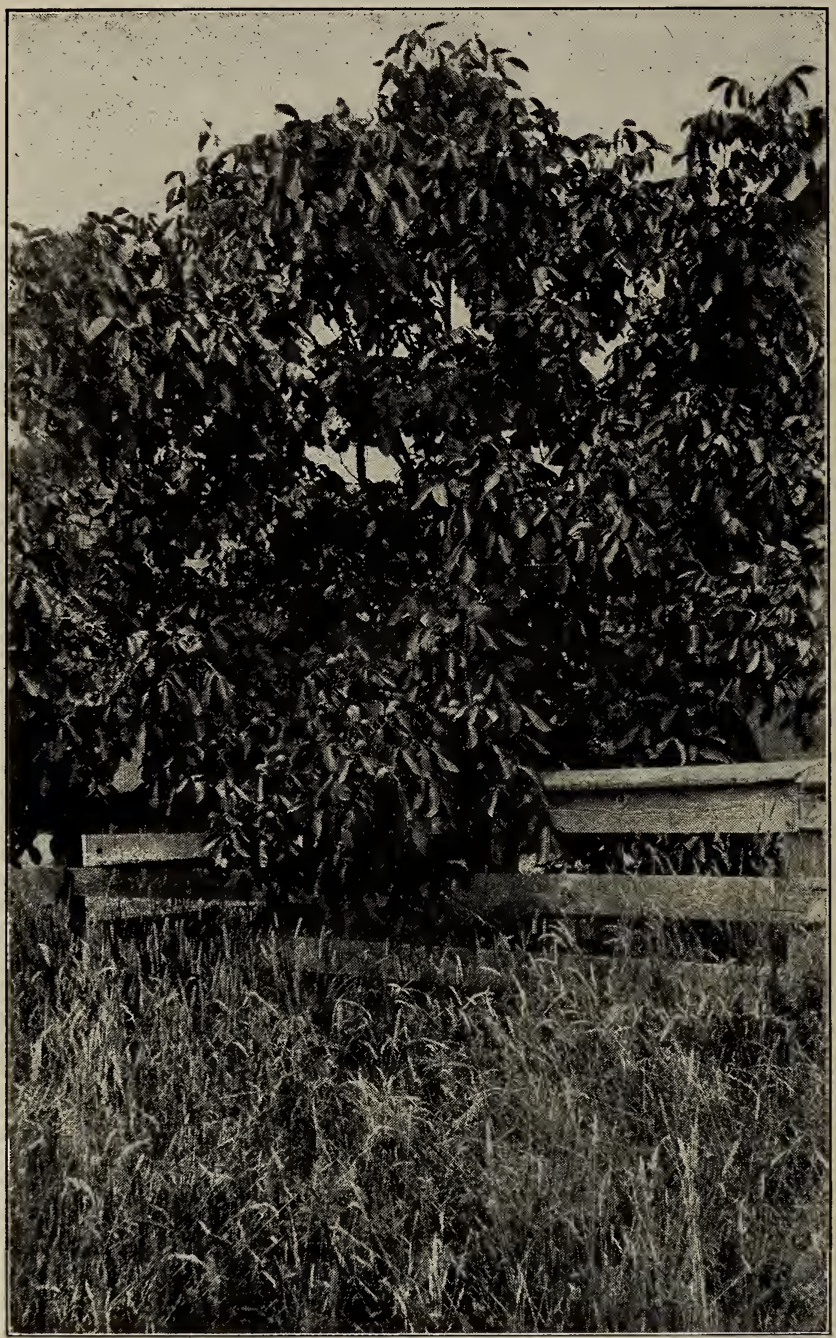

This shows an 8-year-old tree on the farm of Mr. Stratton, near Albany, Ore., showing its early bearing proclivities. This tree is $\mathbf{5}$ years old from transplanting.

"I have an English Walnut tree on my place $1 \frac{1}{4}$ miles from Talent, which is now about 12 years old. This tree began bearing when 5 or 6 years old and has borne every year since. Last year it had over 100 pounds of nuts and this year I am sure there are twice as many. This tree has had no pruning, spraying or care of any kind. My only regret is that I did not put out a commercial orchard." -F. S. McDonald, Talent, Oregon. 


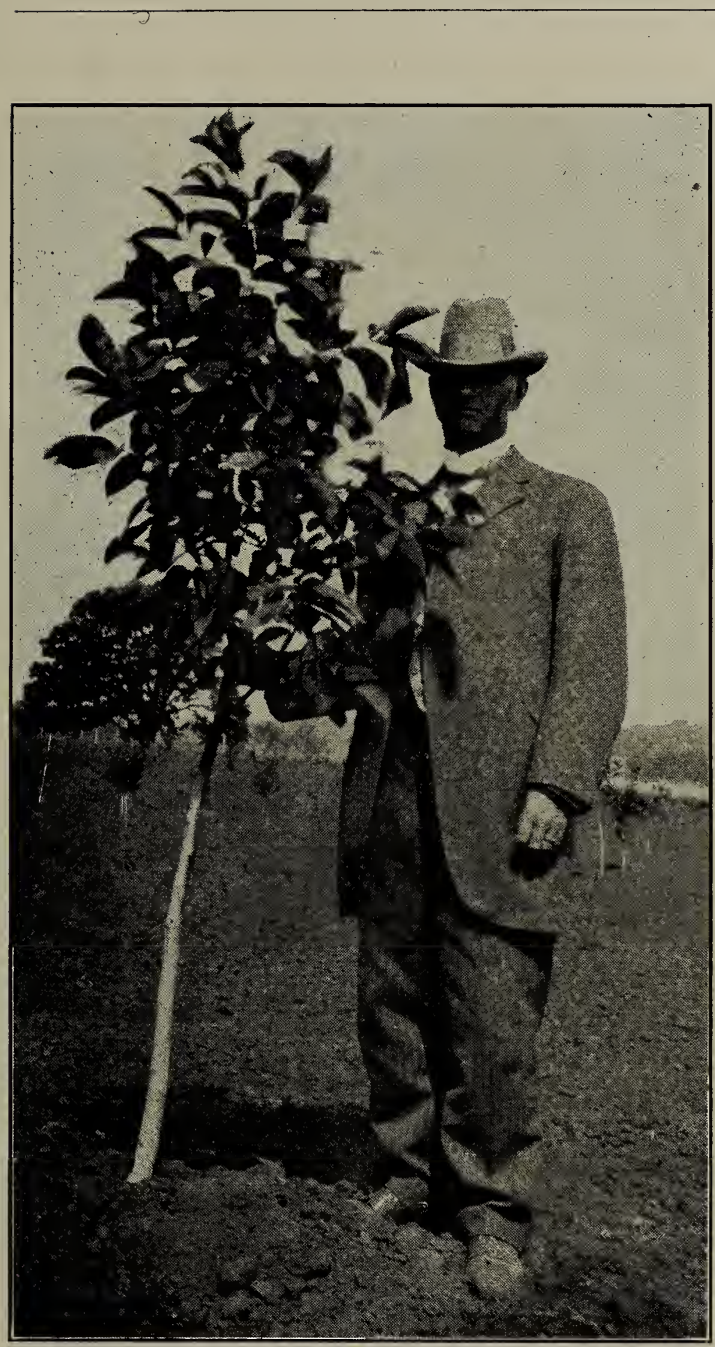

"I firmly believe that the Franquette Walnut will be the best paying crop that can be grown here, and that on account of its blooming so much later than most other varieties it will escape the late Spring frosts. In 23 years residence here I have turned from the apple and pear andpinned my faith to the walnut. Have visited the large groves both in Oregon and California, and each visit makes me more enthusiastic over our possibilities here. Beside a few old bearing trees I have ten acres in walnuts, mostly 3 and 5 years of age, and will plant the balance of my place this season. Am growing trees at present under several conditions. Have some planted in an irrigated alfalfa meadow with only a small circle spaded around the tree and these have made a better growth than those in the cultivated area, due mainly to shading I believe. It will probably pay to shade young trees for at least two seasons. In conclusion, wish to emphasize the fact that the main thing in favor of the walnut is the low cost of growing the trees and ease of harvesting the crop with a very small expense account. It is not the selling price we are so much after as it is the amount left after all expenses are paid. This is where the walnut is a winner."-E. E. Foss, R. F. D. 1, Talent, Oregon.

Mr. E. W. Fish, of Salem, Ore., and one of his Vrooman Franquette trees, second year from planting. The surroundings show that Mr. Fish is a thorough horticulturist and appreciates the value of intelligent cultivation.

"In my grove of English walnuts there are 15 trees running from 7 to 9 inches in diameter six inches from the ground. They were planted in 1906, being 1 year old at time of planting. When four years old they bore a few nuts, perhaps a dozen; about 125 pounds at seven, and this, the eighth year, there will be a still further gain. The soil is a gravelly, clay loam; perhaps 20 inches under this a compact clay gravel, seemingly hard to penetrate, but the roots work down under it somehow. Trees have had clean cultivation and fairly good care. Personally I am well satisfied for the nuts are of fine quality and size. I see no reason why the English (or Persian) walnut should not do well in this part of the state if planted right and taken care of properly." -W. J. DEAN, Talent, Ore. 
TWELVE TIMES AS MANY WALNUTS CONSUMED AS ALL OTHER KINDS OF NUTS COMBINED.

"Five years ago I purchased from your company sufficient walnut trees of the Vrooman Franquette variety to plant 35 acres-thirty acres of grafted trees the balance 1-year-old seedlings. The grafted ones have done fine and I gathered my first crop this year; while few in number they are well filled and large, which the photograph I am sending you will show-six of the nuts measuring 12 inches.

"I believe from observation, the Franquette (Vrooman) the best variety for Oregon plantings and am much encouraged as to the outlook for walnut growing in this state. I have asked several grocerymen what proportion of walnuts they sell as compared with other nuts, and the average is nearly TWELVE TIMES AS MANY WALNUTS AS ALL OTHER NUTS Combined. People are beginning to know the food value of walnuts and when they realize that ONE POUND OF WALNUTS (varieties like the Franquette) CONTAINS AS MUCH NUTRIMENT AS THREE POUNDS OF BEEF OR MUTTON there will be more eaten and some of the high cost of living will be solved.

"I would not take less than $\$ 1000$ per acre for my walnut planting at this time."--Dr. F. H. Walgamot, Portland, Ore., Dec. 2, 1913.

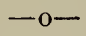

\section{"BEST WALNUTS WE HAVE EVER EATEN."}

"Both your communications under date of the 1st were duly recei ved, together with the generous supply of Vrooman Franquette Walnuts, which we do not hesitate to pronounce the best walnuts we have ever eaten."-GLEN Bros., INC., Per E. S. Mayo, President; Rochester, N. Y., Dec. 16, 1913.

\section{"I WISH I HAD PLANTED MORE."}

"The Vrooman Franquette Walnut trees you sent me came all O. K. I am so well pleased with them that I now wish I had ordered more. Have you any more of the same size and kind on hand."-J. A. Copeland, Myrtle Creek, Ore., March 10, 1913.

(The size Mr. Copeland has reference to is our 5 to 6 foot grade, the kind. we recommend as giving the best satisfaction and results.) -

$$
-0-
$$

\section{MR. HANLEY SAYS HE HAS FOUND WALNUT TREES THE EASIEST OF ALL TREES TO TRANSPLANT.}

"Five years ago I planted 35 second generation walnut trees-thirty being of the Franquette and five of the Mayette varieties. They all lived and those that have not been broken off or planted in the shade of larger trees have made an excellent growth with little care.

"I have found them the easiest of all trees to transplant. Their lateness in budding in the spring will make them a success as a nut tree in this valley"A. E. HANLEY, Central Point, Ore., Oct. 27, 1913. 


\section{Ornamental as Well as Useful}

Not only is the Vrooman Franquette tree a very desirable orchard tree, but it stands high as an ornamental shade tree for planting on the grounds around a residence. It also makes a splendid avenue or street tree. What would be nicer than to plant a row of Vrooman Franquettes on either side of a driveway leading from your home to the road, or planting a row of trees along the front of your property? It would only be a few years until these trees would be producing a crop sufficient to more than pay your taxes. They are to be preferred to the average shade tree, such as maples, elms, etc., and besides giving the same service as these trees, will produce a profitable crop as well. The Vrooman Franquette should be included in every home orchard, along with other lines of fruit.

\section{The Tree We Recommend}

On Page 3 you will find a partial view showing the kind of trees we are selling. They are large, heavy rooted, clean, first-class trees. Experience has demonstrated that a large walnut tree with a good strong constitution and heavy root system transplants more su scessfully than does a smaller tree. We consider the larger tree the most satisfactory and economical in the long run.

\section{The Time to Flant Is-Now}

Don't put off planting at least a few Vrooman Franquette walnut trees. Nothing increases the value of your property like good nursery stock, and particularly walnuts. Trees planted now will be yielding you nuts for your own use at least in a few short years, and by that time the demand for walnuts, based on the increase of the past few years, will be such that your trees will be worth a good deal of money. As an illustration of the value of these trees we cite this incident: About three years ago one of our salesmen sold a man in this Valley several walnut trees with the understanding that in two years time if he was not satisfied the salesman would take back the trees and refund the money. When the appointed time came the salesman called on his friend, stating that he had come for the walnut trees, according to the agreement made at the time of the sale. To make a long story short, the customer stated he would not consider selling those trees for $\$ 10$ each. You will be in exactly the same position a few years hence if you will plant some trees now.

\section{FILBERTS}

$\widetilde{\mathbb{U}}^{\mathrm{B}}$

HE FILBERT, or Hazel as it is often called, is best suited of all nut-bearing trees to garden culture. They are generally described as shrubs or low trees. In "Nut Culture in the United States" published by the United States Department of Agriculture, it states:

"All are unisexual, having staminate blossoms in catkins, developed in the axils of the leaves, on the wood growth of the previous year. The catkins are visible as early as August of the previous season, and in March and April scatter the pollen freely. The pistilate blossoms compose a star-like tuft of crimson stigmas projecting beyond the short, scaly bud, the inner scales of which keep pace with the growth of the enlarging pistils so as to nearly or wholly enclose it 
at maturity. The pistillate blossoms sometimes bloom later in the spring than the staminate ones on the same bush, and in such cases it is necessary to supply pollen from other sources, at the proper time, to secure crops of nuts."

In this section the Barcelona blossom in January and du Chilly in February.

A. A. Quarnberg, the nut expert of Clarke County, Washington, says:

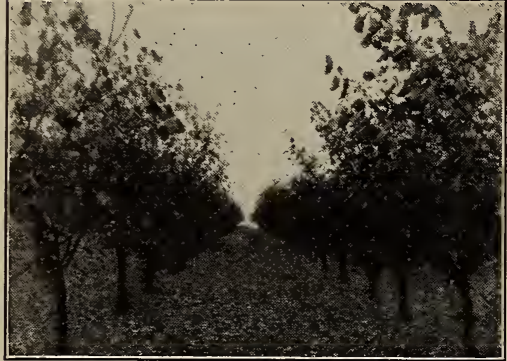

Filbert Orchard of A. A. Quarnberg, Clarke County, Washington.

"The Filbert is another commercial nut of much promise in the Northwest, which by climatic conditions is especially adapted to its culture. The Filberts consumed in the United States must either be produced in the Northwest or continue to be imported from foreign countries, as repeated efforts to raise them in Eastern and Southern states have been so discouraging that the business has now practically been abandoned. There is, therefore, a ready market for almost any amount of Filberts that may be grown in this part of the country, and favorable conditions for their culture is a valuable asset and a resource worth developing.

"The industry is yet in its infancy, but is expected to advance more rapidly now that it is known that it can be made a success. The Filbert is not generally known and appreciated as it deserves to be, a good Filbert is mild and a fine flavor.

"As far as known the first experimental Filbert trees of European varieties were planted in Clarke County in the spring of 1894 by Nat. M. Norelius, Henry J. Biddle and the writer. In the following years others planted in small quantities, but it remained for John E. Norelius in 1900 to set out enough trees, 300 in number, to be called an orchard, and which at that time was the largest Filbert orchard in the Northwest. Each year has since added to the number of planted trees so the time is not far distant when Filbert culture will be numbered among the important industries of the country."

The soil and climate of Southwestern Washington and the Willamette Valley has been demonstrated to be well adapted to Filbert raising, by growing the largest and finest of European varieties for a number of years, and the superior quality can easily be proven by tasting them.

\section{FILBERTS AS FILLERS.}

The Filbert is well adapted to be used as a filler for Walnut orchards as it will come into bearing early and will never reach a height to interfere with the Walnut trees and may be easily removed when the Walnuts need all the space. They are usually grown in tree form and not as bushes when planted in commercial orchards, and are usually planted about 10 feet each way.

"The thin, unfruitful twigs are removed and the fruitful limbs shortened back nearly to the female buds. Care should be taken to leave sufficient male catkins for an ample supply of pollen. The fruit spurs are near the extermities of the last years growth, and nuts are more abundant where light and air have ready access. In the fifth or sixth year trees should bear considerable fruit.; Trees of this age in England are reported to produce 3 to 4 pounds of nuts each," says "Nut Culture in the United States."

Successful Filbert orchards are also grown at Monmouth, Springfield, Eugene, Shaw, Corvallis and other points in the Willamette Valley.

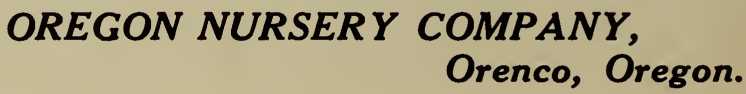




\section{We DO NOT offer Seedling Filberts for sale.}

By Felix Gillet, the nut specialist for so many years at Nevada City, Calif.:

"No nut tree, we beleive, is so little understood as this pretty little member of the great nut family, the Filbert. We have heard of filbert growers grubbing up their 'bushes' because they would not bear. That there is a misunderstanding in regard to filbert culture is obvious. We will give a short sketch on its cultivation and training and how to make it bear.

"Whether Filberts are planted orchard-like, or in cordons around a field, or along a ditch, or in rows through an orchard or vineyard, or in groups, they should in every instance, to bear well, be trained as a tree and not as a bush. It is as easy to train a filbert as a standard or a half standard tree as any other nut or fruit tree. It is true that the filbert, especially when young, has a great tendency to grow sprouts from the roots. These should be unmercifully grubbed whenever showing themselves.

"In the field or orchard, where the filbert is planted solely for its crop of nuts, the trees should be made to branch at 20 to 30 inches.

"Filberts should not be planted closer than 12 feet, or from 12 to 15 feet in rows; but a very important point, to make the tree bear well, is to plant the rows wide apart.

"Of all classes of nuts and fruit trees, none is more benefitted by constant moisture than the filbert.

"We should think the great Northwest, especially Oregon and Washington in the western part, would be admirably adapted to its culture, as the conditions of soil and climate in that part of the country are so favorable to the filbert and do not see, if trees are planted as we suggest, why it should not bear as well there as it does in England; where so many filberts are raised.

"As the filbert deteriorates at once from seed, it should be raised altogether from layering or divisions from the trees themselves grown from layers and therefore able to furnish plants absolutely true. We have grown large filbert trees from seed, and of all the varieties described in our catalogue, and we can assure the public that it is of of no use to try the experiment, for in every case, without one exception, the trees so grown, though bearing well, have borne very small nuts, much smaller than the mother stock, and with filberts as with other nuts the larger ones only are marketable. As a matter of course, rooted layers sell at much higher price than seedlings."

"The Barcelona has proven a free grower especially. A careful examination shows a 10-year-old Barcelona to measure as follows: Trunk circumference 18 1-2 inches; spread of top 16 feet; height over 12 feet. With ordinary care the Barcelona began bearing at 2 years and have borne steadily ever since. This year [1913] we took 15 pounds of salable nuts per tree from this variety."-J. E. Towle, Shaw, Ore., Jan. 10, 1914.

We offer both imported stock and also stock home grown from bearing orchards. We specially recommend the home grown stock, although a little higher in price, as we know the trees from which the layers and divisions are made. The Barcelona and du Chilly are the ones that do the best with us. A few of the English and Cob Nuts could be planted for fertilizing as they are both large sized nuts, but have not proven as heavy bearers. We offer in 12 to 15 inches, 18 to.24 inches and 2 to 3 feet in size.

All the Filberts we offer for sale are rooted layers or rooted divisions. We have never offered any of the cheap seedling Filberts. 


\title{
Oregon Nursery Company
} Orenco, Oregon

\author{
Extensive Growers of
}

Fruit, Shade and Ornamental Trees Flowering Shrubs, Roses, Vines, Etc. Introducers of the Famous

Vrooman Franquette Walnut

Positions Open for Capable Salesmen 